\title{
Few modifiable factors predict readmission following radical cystectomy
}

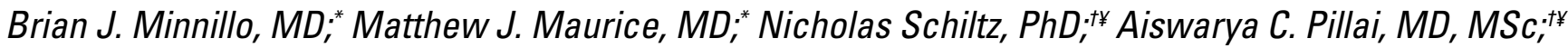 \\ Siran M. Koroukian, PhD; ; Firouz Daneshgari, MD; ${ }^{*}$ Sim P. Kim, MD, MPH; ${ }^{*}$ Robert Abouassaly, MD, MSc
}

*Urological Institute, University Hospitals Case Medical Center, Case Western Reserve University, Cleveland, OH; 'Department of Epidemiology and Biostatistics, Case Western Reserve University, Cleveland, $\mathrm{OH}$; §Yale University, COPPER Center, New Haven, CT; *Population Health and Outcomes Research Core, Clinical and Translational Science Collaborative, Cleveland, $\mathrm{OH}$

Cite as: Can Urol Assoc J 2015;9(7-8):E439-46. http://dx.doi.org/10.5489/cuaj.2793 Published online July 17, 2015.

\section{Abstract}

Introduction: We sought to determine the patient and providerrelated factors associated with readmission after radical cystectomy (RC) for bladder cancer. In this era of healthcare reform, hospital performance measures, such as readmission, are beginning to affect provider reimbursement. Given its high readmission rate, RC could be a target for quality improvement.

Methods: We reviewed bladder cancer patients who underwent RC in California's State Inpatient Database (2005-2009) of the Healthcare Cost and Utilization Project. We examined patient(e.g., race, discharge disposition) and provider-related factors (e.g., volume) and evaluated their association with 30-day readmission. Multivariable logistic regression was used to examine associations of interest.

Results: Overall, 22.8\% ( $\mathrm{n}=833)$ of the 3649 patients who underwent RC were readmitted within 30 days. Regarding disposition, $34.8 \%, 50.8 \%$, and $12.2 \%$ were discharged home, home with home healthcare, and to a post-acute care facility (PACF), respectively. Within 30 days, $20.3 \%, 20.9 \%$, and $42.3 \%$ were discharged home, home with home healthcare, and to a PACF were readmitted, respectively. African Americans (odds ratio [OR] 1.64, 95\% confidence interval $[\mathrm{Cl}]$ 1.07-2.50), having $\geq 2$ comorbidities (OR 1.42, 95\% Cl 1.06-1.91), receiving a neobladder (OR 1.45, 95\% $\mathrm{Cl} 1.09-1.93$ ), and discharged to a PACF (OR $3.79,95 \% \mathrm{Cl}$ 2.88-4.98) were independent factors associated with readmission. Hospital stays $\geq 15$ days were associated with less readmission (OR 0.43, 95\% Cl 0.27-0.67, $p=0.0002$ ). Procedure volume was not associated with complication, in-hospital mortality, or readmission.

Conclusions: About one-fifth of patients undergoing RC are readmitted. Patients who are discharged to a PACF, African American, and who have more extensive comorbidities tend to experience more readmissions. Increased efforts with care coordination among these patients may help reduce readmissions.

\section{Introduction}

Since passage of the Patient Protection and Affordable Care Act in 2010, hospital readmission has become an essential healthcare quality metric., ${ }^{1,2}$ Centers for Medicare and Medicaid Services began penalizing hospitals with decreased Medicare payments for excessive readmissions in pneumonia, heart failure, and myocardial infarction. The policy will expand to include elective hip arthroplasty and knee arthroplasty, ${ }^{2}$ while other elective procedures resulting in unplanned readmissions will be added. ${ }^{3}$ Still, there is debate whether readmission reflects hospital quality and whether medical care readmission is comparable to surgical readmission.

Clinical leaders and hospital executives are concerned as reports show hospitals, such as teaching hospitals and safetynet hospitals (top quartile of hospitals providing uncompensated care), caring for sicker patients are more likely to have readmissions and thus incur disproportionate penalty. ${ }^{4}$ Medical literature has shown 30-day readmission rates in heart failure and pneumonia are related to disease severity and socioeconomic status. ${ }^{5} \mathrm{~A}$ large Medicare analysis from 479471 discharges after 6 major surgeries (non-urologic) revealed a risk-adjusted readmission rate of $13.1 \%$ with higher-volume and lower mortality hospitals yielding slightly lower 30-day readmission. ${ }^{6}$ Since readmission is variable and fairly high for many major surgeries, at which level should hospitals be penalized?

Across all surgical disciplines, including urology, the relationship between surgical care and readmission is underappreciated. Radical cystectomy (RC) may face scrutiny since it is associated with complication rates up to $68 \%$ and readmission rates as high as $26 \%$ even when performed at centres of excellence..$^{7-9}$ Given this data, RC could be a target quality improvement area. Therefore, our objective was to determine patient- and provider-related factors associated with 30-day readmission after RC. 
Minnillo et al.

\section{Methods}

\section{Data sources}

We used discharge data from California's State Inpatient Database of the Healthcare Cost and Utilization Project (HCUP), an Agency for Healthcare Research and Quality. The HCUP State Inpatient Database (SID) contains the largest collection of longitudinal, all-payer, encounter-level hospital care data in the United States. The national aggregate of SIDs encompasses $97 \%$ of hospital admissions. HCUP California databases allow tracking of patients across different times and practice settings using synthetic patient-level identifiers. SID data were merged with California's Office of Statewide Health Planning and Development hospital database to provide hospital characteristics. Case Western Reserve University's Institutional Review Board approved this study.

\section{Study design and patient characteristics}

From California's SID, we retrospectively analyzed patients diagnosed with bladder cancer from January 2005 to December 2009 ( $n=37$ 615) using the International Classification of Diseases, 9th Edition, Clinical Modification (ICD-9-CM) diagnosis codes. Inclusion criteria included the codes for malignant bladder neoplasm (188.0-188.9), carcinoma-in-situ code (237.7), and bladder neoplasm nototherwise-specified code (239.4). We then used ICD-9-CM procedure codes to identify bladder cancer patients who underwent RC ( $\mathrm{n}=3711$; code 57.71). We excluded all patients with missing synthetic patient identifiers needed to track subsequent hospitalizations $(n=62)$. Thus, the final surgical cohort included 3649 patients.

\section{Objectives, hypothesis, and variables of interest}

Our primary objective was to determine patient- and provider-related factors associated with readmission after RC for bladder cancer. We hypothesized that patients with lower socioeconomic status, advanced age, and increased medical comorbidities had more readmission after cystectomy. We also proposed that hospitals with an academic affiliation and higher surgical volume would have less readmission. We tested this hypothesis by reviewing a large population of RC cases.

We defined our dependent variable, readmission, as a subsequent hospitalization occurring within 30-days from the RC hospital stay. Our independent variables included diagnosis year, age, gender, race, primary insurance (Medicaid, Medicare, self-insured, private), comorbidity category $(0,1,2, \geq 3$ comorbidities), complication category
$(0,1,2, \geq 3$ complications), length-of-stay category $(0-5,6-8$, $9-11,12-14, \geq 15$ days $)$, hospital volume $(<10,10-49, \geq 50$ cystectomies/year), and procedure type. We classified the procedures as neobladder (code 57.87), standard incontinent diversion (codes 56.51, 56.52, 56.71), and other urinary diversion (code 56.79). Hospital characteristics were categorized into academic, profit or non-profit status, and government affiliation. Discharge disposition was classified as routine discharge home, home with home healthcare, and to a post-acute care facility [PACF] (e.g., nursing home or skilled-nursing-facility). Patient comorbidities were identified using ICD-9-CM diagnosis codes (e.g., congestive heart failure, code 428). Treatment-related complications were identified based on associated ICD-9-CM diagnosis and procedure codes obtained from inpatient secondary diagnoses and procedures (Appendix 1, Appendix 2).

\section{Statistical analysis}

We compared continuous variables using student t-test and categorical variables using chi-square test. We performed univariate analysis to assess independent variables associated with 30-day readmission. Next, to adjust for confounding factors, we used multivariable logistic regression to examine the associations of interest. After discovering patients discharged to a PACF had higher readmission, we performed a subanalysis using multinomial regression to identify factors associated with discharge to home, to home with home healthcare, or to PACFs. Comorbidity count was not included in the multinomial model because it caused model convergence and the data were insignificant.

Odds ratio (OR) estimates and 95\% confidence intervals $(\mathrm{Cl})$ were obtained for all levels. Logistic model calibration and discrimination were assessed with c-statistic. Statistical significance was defined as $p$ values less than 0.05. All analyses were done using SAS v9.3 (SAS Institute Inc. Cary, NC).

\section{Results}

\section{Baseline descriptive data}

We identified 3649 patients who underwent RC. The median age was 71 years (interquartile range [IQR] 62-77), with $83.3 \%$ male and $52.9 \%$ aged $\geq 70$. Most patients $(76.0 \%)$ were treated at academic centres. Most patients received surgery at hospitals performing $<10$ cystectomies/year (44.5\%), with most receiving a standard incontinent diversion $(79.6 \%)$ (Table 1).

On univariate analysis, age $(p=0.04)$, comorbidity count $(p=0.003)$, and discharge disposition $(p<0.0001)$ were the only variables associated with increased readmission (Table 2). There were $22.1 \%$ (638), $25.7 \%$ (79), and $25.5 \%$ 


\begin{tabular}{|c|c|}
\hline Variable & All RC patients $n, \%$ \\
\hline Total patients & 3649 \\
\hline 30-day readmissions & $833(22.8)$ \\
\hline Total complications & $2014(55.2)$ \\
\hline In-hospital mortality & $83(2.3)$ \\
\hline Median length-of-stay, days (IQR) & $9(7-13)$ \\
\hline Median age, years (IQR) & $71(62-77)$ \\
\hline \multicolumn{2}{|l|}{ Age categories } \\
\hline$<50$ & $173(4.7)$ \\
\hline $50-59$ & $499(13.7)$ \\
\hline $60-69$ & $1046(28.7)$ \\
\hline $70-79$ & $1322(36.2)$ \\
\hline$\geq 80$ & $609(16.7)$ \\
\hline \multicolumn{2}{|l|}{ Gender } \\
\hline Male & $3042(83.3)$ \\
\hline Female & $607(16.7)$ \\
\hline \multicolumn{2}{|l|}{ Race } \\
\hline White & $2825(77.4)$ \\
\hline Black & $123(3.4)$ \\
\hline Other & $701(19.2)$ \\
\hline \multicolumn{2}{|l|}{ Comorbidity } \\
\hline 0 comorbidity & $487(13.4)$ \\
\hline 1 comorbidity & $910(24.9)$ \\
\hline 2 comorbidities & $849(23.3)$ \\
\hline$\geq 3$ comorbidities & $1403(38.5)$ \\
\hline \multicolumn{2}{|l|}{ Complications } \\
\hline No complications & $1614(44.2)$ \\
\hline 1 complication & $1084(29.7)$ \\
\hline 2 complications & $519(14.2)$ \\
\hline$\geq 3$ complications & $432(11.8)$ \\
\hline \multicolumn{2}{|l|}{ Diversion type } \\
\hline Incontinent diversion & $2887(79.1)$ \\
\hline Neobladder & $307(8.4)$ \\
\hline Other & $455(12.5)$ \\
\hline \multicolumn{2}{|l|}{ LOS category, days } \\
\hline $0-5$ & $175(4.8)$ \\
\hline $6-8$ & $1325(36.3)$ \\
\hline $9-11$ & $1063(29.1)$ \\
\hline $12-14$ & $421(11.5)$ \\
\hline$\geq 15$ & $665(18.2)$ \\
\hline \multicolumn{2}{|l|}{ Hospital volume (no. cystectomies) } \\
\hline$<10$ & $1625(44.5)$ \\
\hline $10-49$ & $1241(34.0)$ \\
\hline$\geq 50$ & $783(21.5)$ \\
\hline \multicolumn{2}{|l|}{ Hospital type } \\
\hline Academic & $2,790(77.2)$ \\
\hline Non-academic & $822(22.8)$ \\
\hline \multicolumn{2}{|l|}{ Disposition } \\
\hline Died & $83(2.3)$ \\
\hline Post-acute care facility & $444(12.2)$ \\
\hline Routine home & $1270(34.8)$ \\
\hline Home healthcare & $1852(50.7)$ \\
\hline
\end{tabular}

(116) readmissions in those who had an incontinent urinary diversion, neobladder, and other diversion, respectively. With respect to discharge, $34.8 \%$ (1270), 50.8\% (1852), and $12.2 \%$ (444) were discharged home, home with home healthcare, and to a PACF, respectively. Within 30 days, $20.3 \%$ (258), 20.9\% (387), and 42.3\% (188) discharged home, home with home healthcare, and to a PACF were readmitted, respectively (Table 2 ).

\section{Short-ferm outcomes}

Thirty-day readmission, postoperative complication, and inhospital mortality rates were $22.8 \%$ (833), 55.2\% (2014), and $2.3 \%(83)$, respectively. Median length-of-stay was 9 days (IQR 7-13), with $18.2 \%$ (665) staying $\geq 15$ days in hospital (Table 1).

Being African American (OR 1.64, 95\% Cl 1.07-2.50, $p=0.02$ ), having $\geq 2$ comorbidities (OR $1.42,95 \% \mathrm{Cl} 1.06-$ $1.91, p=0.02)$, receiving a neobladder reconstruction (OR 1.45, 95\% Cl 1.09-1.93, $p=0.01$ ), and discharge disposition to a PACF (OR 3.79, 95\% Cl 2.88-4.98, $p<0.0001$ ) were independent factors associated with readmission. Patients discharged home with home healthcare were not associated with increased readmission (OR 1.04 $95 \% \mathrm{Cl} 0.87-1.26, p=0.66)$. Hospital stays $\geq 15$ days were associated with less readmission and hospital procedure volume ( $>50$ vs. $<10$ cystectomies/year) was not associated with improved readmission (Table 3).

Multinomial regression revealed that male patients $(p=0.0002)$ and patients with neobladder reconstruction $(p=0.002)$ were less likely to be discharged to a PACF. However, patients $>80$ years $(p \leq 0.0001)$, increased complications count $(p \leq 0.0001)$, and Medicare insurance $(p \leq 0.0001)$ were associated with discharge to a PACF compared to home (Table 4).

\section{Discussion}

Healthcare policymakers are emphasizing improvements in hospital readmissions as a quality improvement initiative believing costs will decrease and overall care will improve with decreases in readmission. Across all surgical disciplines, including urology, the relationship between surgical care and readmission is underappreciated. In our RC analysis, we found two modifiable factors associated with 30-day readmission: being discharged to a PACF and receiving a neobladder reconstruction. We reported a $12.2 \%$ discharge rate to PACFs, which is close to the rate $(16 \%)$ reported by the Agency for Healthcare Research and Quality in 2011. ${ }^{10}$ Despite the low rate, those discharged to a PACF were almost 4 times more likely to be readmitted than those discharged to home after adjusting for confounders. The unexpectedly high $42 \%$ readmission rate from PACFs raises uncertainty in 
Minnillo et al.

Table 2. Univariate analysis of patients readmitted versus those not readmitted

\begin{tabular}{|c|c|c|c|}
\hline Variable & $\begin{array}{l}\text { Patients not readmitted within } 30 \text { days n } \\
(\%)\end{array}$ & $\begin{array}{l}\text { Patients readmitted within } 30 \text { days } \\
\text { n (\%) }\end{array}$ & $p$ value $^{\dagger}$ \\
\hline & $2816(77.2)$ & $833(22.8)$ & \\
\hline \multicolumn{4}{|l|}{ Age categories } \\
\hline$<50$ & $138(4.9)$ & $35(4.2)$ & \multirow{5}{*}{0.04} \\
\hline $50-59$ & 409 (14.5) & 90 (10.8) & \\
\hline $60-69$ & $811(28.8)$ & $235(28.2)$ & \\
\hline 70-79 & $998(35.4)$ & $324(38.9)$ & \\
\hline$\geq 80$ & $460(16.3)$ & $149(17.9)$ & \\
\hline \multicolumn{4}{|l|}{ Gender } \\
\hline Male & $2341(83.1)$ & $701(84.0)$ & \multirow{2}{*}{0.47} \\
\hline Female & 475 (16.8) & $132(15.7)$ & \\
\hline \multicolumn{4}{|l|}{ Race } \\
\hline White & 2180 (77.4) & $645(77.4)$ & \multirow{3}{*}{0.23} \\
\hline Black & $88(3.1)$ & $35(4.2)$ & \\
\hline Other & $548(19.5)$ & $153(18.4)$ & \\
\hline \multicolumn{4}{|l|}{ Insurance } \\
\hline Medicaid/Medicare & 1919 (68.1) & $588(70.5)$ & \multirow{3}{*}{0.43} \\
\hline Private & $820(29.1)$ & $228(27.4)$ & \\
\hline Other & $77(2.8)$ & $17(2.0)$ & \\
\hline \multicolumn{4}{|l|}{ Comorbidity } \\
\hline 0 comorbidities & $401(14.2)$ & $86(10.3)$ & \multirow{4}{*}{0.003} \\
\hline 1 comorbidity & $719(25.5)$ & $191(22.9)$ & \\
\hline 2 comorbidities & $647(23.0)$ & $202(24.2)$ & \\
\hline$\geq 3$ comorbidities & 1049 (37.3) & $354(42.5)$ & \\
\hline \multicolumn{4}{|l|}{ Complications } \\
\hline No complications & $1,246(44.2)$ & $368(44.2)$ & \multirow{4}{*}{0.48} \\
\hline 1 complication & $832(29.6)$ & $252(30.3)$ & \\
\hline 2 complications & $393(14.0)$ & $126(15.1)$ & \\
\hline$\geq 3$ complications & $345(12.3)$ & $87(10.4)$ & \\
\hline \multicolumn{4}{|l|}{ LOS Category } \\
\hline $0-5$ & $133(4.7)$ & $42(5.0)$ & \multirow{5}{*}{0.062} \\
\hline $6-8$ & $1005(35.7)$ & $320(38.4)$ & \\
\hline $9-11$ & $816(29.0)$ & $247(29.7)$ & \\
\hline $12-14$ & $320(11.4)$ & $101(12.1)$ & \\
\hline$\geq 15$ & $542(19.3)$ & $123(14.8)$ & \\
\hline Type of diversion & & & 0.12 \\
\hline Incontinent diversion & 2249 (79.9) & $638(76.6)$ & \\
\hline Neobladder & $228(8.1)$ & $79(9.5)$ & \\
\hline Other & $339(12.0)$ & $116(13.9)$ & \\
\hline \multicolumn{4}{|c|}{ Hospital volume (no. cystectomies) } \\
\hline$<10$ & $1244(44.2)$ & $381(45.7)$ & \multirow{3}{*}{0.71} \\
\hline $10-49$ & $966(34.3)$ & $275(33.0)$ & \\
\hline$\geq 50$ & $606(21.5)$ & $177(21.2)$ & \\
\hline \multicolumn{4}{|l|}{ Hospital type } \\
\hline Academic & $2163(76.8)$ & $627(75.3)$ & \multirow{2}{*}{0.41} \\
\hline Non-academic & $626(22.2)$ & $196(23.5)$ & \\
\hline \multicolumn{4}{|l|}{ Disposition } \\
\hline Died & $83(2.9)$ & $0(0.0)$ & \multirow{4}{*}{$<0.0001$} \\
\hline Post-acute care facility & $256(9.1)$ & $188(22.6)$ & \\
\hline Routine home & $1012(35.9)$ & $258(31.0)$ & \\
\hline Home healthcare & $1465(52.0)$ & $387(46.5)$ & \\
\hline
\end{tabular}

LOS: length of stay. TChi square test between those readmitted and not readmitted. 


\begin{tabular}{|c|c|}
\hline Variable & OR (95\% Cl) \\
\hline \multicolumn{2}{|l|}{ Age, years } \\
\hline $50-59$ vs. $<50$ & $0.88(0.56-1.38)$ \\
\hline $60-69$ vs. $<50$ & $1.12(0.73-1.71)$ \\
\hline $70-79$ vs. $<50$ & $1.25(0.80-1.95)$ \\
\hline$\geq 80$ vs. $<50$ & $1.06(0.66-1.70)$ \\
\hline \multicolumn{2}{|l|}{ Race } \\
\hline African American vs. Caucasian & $1.64(1.07-2.50)$ \\
\hline Other vs. Caucasian & $1.22(0.69-2.16)$ \\
\hline \multicolumn{2}{|l|}{ Comorbidity } \\
\hline 1 comorbidity vs. 0 & $1.27(0.95-1.70)$ \\
\hline 2 comorbidities vs. 0 & $1.42(1.06-1.91)$ \\
\hline 3 comorbidities vs. 0 & $1.56(1.17-2.07)$ \\
\hline \multicolumn{2}{|l|}{ Complications } \\
\hline 1 complication vs. no complications & $1.02(0.84-1.23)$ \\
\hline 2 complications vs. no complications & $1.11(0.86-1.44)$ \\
\hline$\geq 3$ complications vs. no complications & $0.90(0.65-1.24)$ \\
\hline \multicolumn{2}{|l|}{ LOS category, days } \\
\hline LOS 6-8 vs. LOS 0-5 & $0.92(0.62-1.34)$ \\
\hline LOS 9-11 vs. LOS 0-5 & $0.81(0.55-1.21)$ \\
\hline LOS $12-14$ vs. LOS 0-5 & $0.71(0.46-1.11)$ \\
\hline LOS $\geq 15$ vs. LOS $0-5$ & $0.43(0.27-0.67)$ \\
\hline \multicolumn{2}{|l|}{ Neobladder } \\
\hline Neobladder vs. no neobladder & $1.45(1.09-1.93)$ \\
\hline \multicolumn{2}{|l|}{ Hospital volume (no. cystectomies) } \\
\hline $10-49$ vs. $<10$ & $1.04(0.83-1.30)$ \\
\hline$\geq 50$ vs. $<10$ & $1.10(0.81-1.51)$ \\
\hline \multicolumn{2}{|l|}{ Hospital type } \\
\hline Academic vs. non-academic & $1.00(0.78-1.28)$ \\
\hline \multicolumn{2}{|l|}{ Disposition } \\
\hline Home healthcare vs. routine home & $1.04(0.87-1.26)$ \\
\hline Post-acute care facility vs. routine home & $3.79(2.88-4.98)$ \\
\hline OR: odds ratio; Cl: confidence interval; LOS: length of stay. & \\
\hline
\end{tabular}

the facilities ability to handle complex post-surgical patients. Potential reasons for readmission from PACFs include: lack of knowledge caring for urostomies, continent diversions, surgical drains or gastrointestinal/nutritional status in cystectomy patients. However, there may be selection bias since patients admitted to PACFs are likely older and sicker with a more complicated initial hospital stay. A smaller cystectomy series $(n=400)$ from 2004 to 2007 from Vanderbilt researchers revealed no difference in readmission based on discharge to a facility compared to home or home with home healthcare. ${ }^{11}$ Yet, they reported readmission rates between $32 \%$ and $38 \%$ for all types of discharge. In general surgery literature, discharge disposition to skilled care facilities has been associated with frequent readmissions, increased mortality, delayed recovery, and diminished quality of life. ${ }^{12}$

Increased length-of-stay was associated with decreased readmission, except for patients discharged between 0 to

\begin{tabular}{|c|c|}
\hline Variable & OR $(95 \% \mathrm{Cl})$ \\
\hline \multicolumn{2}{|l|}{ Age, years } \\
\hline $50-59$ vs. $<50$ & $0.91(0.38-2.18)$ \\
\hline $60-69$ vs. $<50$ & $1.18(0.53-2.65)$ \\
\hline $70-79$ vs. $<50$ & $1.95(0.86-4.41)$ \\
\hline$\geq 80$ vs. $<50$ & $5.31(2.31-12.2)$ \\
\hline \multicolumn{2}{|l|}{ Race } \\
\hline African American vs. Caucasian & $0.83(0.44-1.60)$ \\
\hline Other vs. Caucasian & $0.64(0.20-2.01)$ \\
\hline \multicolumn{2}{|l|}{ Sex } \\
\hline Male vs. female & $0.57(0.42-0.77)$ \\
\hline \multicolumn{2}{|l|}{ Insurance } \\
\hline Medicaid vs. private & $1.26(0.63-2.53)$ \\
\hline Self vs. private & $1.89(0.49-7.25)$ \\
\hline Medicare vs. private & $2.70(1.82-4.02)$ \\
\hline \multicolumn{2}{|l|}{ Complications } \\
\hline 1 complication vs. no complications & $1.77(1.31-2.40)$ \\
\hline 2 complications vs. no complications & $3.02(2.12-4.29)$ \\
\hline$\geq 3$ complications vs. no complications & $7.63(5.30-10.9)$ \\
\hline \multicolumn{2}{|l|}{ Neobladder } \\
\hline Neobladder vs. no neobladder & $0.35(0.18-0.67)$ \\
\hline \multicolumn{2}{|l|}{ Hospital volume (no. cystectomies) } \\
\hline 10 to 49 vs. $<10$ & $1.17(0.84-1.63)$ \\
\hline$\geq 50$ vs. $<10$ & $1.17(0.72-1.90)$ \\
\hline \multicolumn{2}{|l|}{ Hospital type } \\
\hline Academic vs. non academic & $0.57(0.41-0.80)$ \\
\hline
\end{tabular}

5 days, although less than $5 \%$ of patients were discharged by day 5 . An increased length-of-stay is viewed as having significant postoperative events, poor outcomes, and higher costs, but our data showed the opposite regarding readmission. Determining whether a lengthy primary hospital stay, short primary stay along with an indeterminate readmission length, or short primary stay along with a PACF stay is the best patient-centered and cost-conscious approach could be studied further. Potential reasons for decreased readmission in these patients include: complete return of bowel function, improved mobility, better wound healing, and longer prophylaxis for venous thromboembolism prior to discharge.

Surgeons generally select younger, healthier, more motivated patients for neobladder reconstruction. Yet, these patients had a $45 \%$ increased chance of readmission. Our data illustrate a need for greater perioperative counselling and attention to discharge planning in this cohort. Interestingly, neobladder cases were less likely to be discharged to PACFs possibly for the reasons mentioned above (facilities might not be comfortable managing reconstructive bladders). Alternatively, these patients may be younger, healthier, more educated with a stronger social support 
allowing discharge to home. Regardless, increased efforts with care coordination among neobladder patients may help reduce readmissions.

Although cystectomy cases are not subject to readmission penalties, hospitals may need to prepare for such inspection because there is high perioperative morbidity. We confirmed the morbidity revealing a $22.8 \%$ readmission, $55.2 \%$ complication, and $2.3 \%$ in-hospital mortality rate, which is similar to other published series.--9,13,14 We also revealed that treatment at higher-volume centres or academic centres was not protective or predictive of readmission. Academic centres were less likely to discharge patients to PACFs, which may be protective. Finally, since readmission is variable and fairly high for many major surgeries, at which level should hospitals be penalized? Adjustments for coexisting medical and social conditions may be needed to equalize hospital penalties.

The number of complications predicted early mortality but not hospital readmission, while the number of postoperative complications was associated with discharge to PACFs, which was associated with readmission. Other non-urologic studies have shown readmission increases as complications increase with up to a 4 -fold increase in readmission with 1 or more complications. ${ }^{15,16}$ The reasons for the differences may be due to the type of surgery, geographic location, or other unmeasured confounders. Previous reports have demonstrated worse outcomes based on race in bladder cancer. Possible explanations included delay in seeking care, presentation with advanced disease, and receiving surgery at lower-volume hospitals. ${ }^{17,18}$ External data regarding readmission based on race are limited, but our data showed that the African American race was associated with an increased 30-day readmission.

Despite its strengths, there are limitations to our study. It is retrospective with inherent biases and the data reliability depends on how the variables were measured and recorded. Certain variables, such as patient performance status, surgeon volume, and case complexity, were not available. Although our study population included all patients in California, referral patterns may influence outcomes in certain circumstances. This could affect readmission interpretation related to hospital volume and academic affiliation. For example, academic hospitals likely do more complex cases that may result in a higher readmission rate. We reported similar readmission rates, which might actually indicate the academic centres are doing well. Also, this dataset does not have cancer staging or grade information or final pathology that could influence postoperative outcomes.

\section{Conclusion}

Cystectomy stands to face critical review in the "pay for performance" era, as about one-fifth of patients are readmitted within 30 days of surgery. Patients who are discharged to a
PACF, African American, and with more extensive comorbidities had higher readmissions. Increased efforts with care coordination among these patients may help reduce readmissions.

Acknowledgements: This publication was made possible by the Clinical and Translational Science Collaborative of Cleveland, ULITR000439 from the National Center for Advancing Translational Sciences (NCATS) component of the National Institutes of Health and NIH roadmap for Medical Research. Its contents are solely the responsibility of the authors and do not necessarily represent the official views of the NIH.

Competing interests: The authors declare no competing financial or personal interests.

This paper has been peer-reviewed.

\section{References}

1. The Patient Protection and Affordable Care Act, HR 3590, 111th Cong, 2nd Session, 2010.

2. The Patient Protection and Affordable Care Act, HR 3590, 111th Cong, 2nd Session, 2010. Addended section 3025 with section 1886(q)-The Hospital Readmissions Reduction Program. http://www.cms. gov/Medicare/Medicare-Fee-for-Service-Payment/AcutelnpatientPPS/Readmissions-Reduction-Program. html. Accessed July 2, 2015.

3. Kocher RP, Adashi EY. Hospital readmissions and the Affordable Care Act: Paying for coordinated quality care. JAMA 2011;306:1794-5. http://dx.doi.org/10.1001/jama.2011.1561

4. Joynt KE, Jha AK. Characteristics of hospitals receiving penalties under the Hospital Readmissions Reduction Program. JAMA 2013;309:342-3. http://dx.doi.org/10.1001/jama.2012.94856

5. Joynt KE, Orav EJ, Jha AK. Thirty-day readmission rates for Medicare beneficiaries by race and site of care. JAMA 2011;305:675-81. http://dx.doi.org/10.1001/jama.2011.123

6. Tsai TC, Joynt KE, Orav EJ, et al. Variation in surgical-readmission rates and quality of hospital care. $N$ Engl J Med 2013;369:1134-42. http://dx.doi.org/10.1056/NEJMsa1303118

7. Jacobs BL, Zhang $\mathrm{Y}$, Tan $\mathrm{HJ}$, et al. Hospitalization trends after prostate and bladder surgery: Implications of potential payment reforms. J Urol 2013;189:59-65. http://dx.doi.org/10.1016/i.juro.2012.08.182

8. Johar RS, Hayn MH, Stegemann AP, et al. Complications after robot-assisted radical cystectomy: Results from the International Robotic Cystectomy Consortium. Eur Urol 2013;64:52-7. htrp://dx.doi. org/10.1016/i.eururo.2013.01.010

9. Stimson CJ, Chang SS, Barocas DA, et al. Early and late perioperative outcomes following radical cystectomy: 90-day readmissions, morbidity and mortality in a contemporary series. J Urol 2010;184:1296-300. http://dx.doi.org/10.1016/i.juro.2010.06.007

10. Agency for Health Care Quality Research HCUPnet. Outcomes by patient and hospital characteristics for all discharges in 2011. hitp://hcupnet.ahrq.gov/HCUPnet.jsp. Accessed July 2, 2015.

11. Aghazadeh MA, Barocas DA, Salem S, et al. Determining factors for hospital discharge status after radical cystectomy in a large contemporary cohort. J Urol 2011;185:85-9. http://dx.doi.org/10.1016/i. juro.2010.08.016

12. Legner VJ, Massarweh NN, Symons RG, et al. The significance of discharge to skilled care after abdominopelvic surgery in older adults. Ann Surg 2009;249:250-5. http://dx.doi.org/10.1097/ SLA.0b013e318195e12f

13. Konety BR, Allareddy V. Influence of post-cystectomy complications on cost and subsequent outcome. $J$ Urol 2007;177:280-7; discussion 287. http://dx.doi.org/10.1016/i.juro.2006.08.074

14. Hu M, Jacobs BL, Montgomery JS, et al. Sharpening the focus on causes and timing of readmission after radical cystectomy for bladder cancer. Cancer 2014;120:1409-16. http://dx.doi.org/10.1002/ cncr.28586

15. Lawson EH, Hall BL, Lovie R, et al. Association between occurrence of a postoperative complication and readmission: Implications for quality improvement and cost savings. Ann Surg 2013;258:10-8. http:// dx.doi.org/10.1097/SLA.0b013e31828e3ac3

16. Kassin MT, Owen RM, Perez SD, et al. Risk factors for 30-day hospital readmission among general surgery patients. J Am Coll Surg 2012;215:322-30. http://dx.doi.org/10.1016/i.jamcollsurg.2012.05.024 
17. Prout GR Jr, Wesley MN, Greenberg RS, et al. Bladder cancer: Race differences in extent of disease at diagnosis. Cancer 2000;89:1349-58. http://dx.doi.org/10.1002/1097-0142(20000915)89:6<1349::AIDCNCR20 $>3.0 . C 0 ; 2-D$

18. Konety BR, Allareddy V, Carroll PR. Factors affecting outcomes after radical cystectomy in African Americans. Cancer 2007;109:542-8. http://dx.doi.org/10.1002/cncr.22449
Correspondence: Dr. Robert Abouassaly, Assistant Professor, Department of Urology, Case Western Reserve University, Urological Institute, University Hospitals Case Medical Center, Mailstop LKD 5046, Office 4576, 11100 Eudlid Ave., Cleveland, 0H; robert.abouassaly@uhhospitals.org

\begin{tabular}{ll}
\hline Appendix 1. Diagnosis codes used to calculate the comorbidity count \\
\hline Diagnosis & ICD-9-CM Codes \\
\hline Myocardial infarction & 410,412 \\
Congestive heart failure & 428 \\
Peripheral vascular disease & $433.9,441,7854$, V433 \\
Cerebrovascular disease & $430-438$ \\
Dementia & 290 \\
Pulmonary disease & $490-496,500-505$ \\
Connective tissue disorder & $7100,7101,7104,7140,7141,7142,71481,725$ \\
Peptic ulcer & $531-534$ \\
Liver disease & $5712,5714,5715,5716$ \\
Diabetes & $2500-2503,2507$ \\
Diabetes complications & $2504-2506$ \\
Paraplegia & 342,3441 \\
Renal disease & $582,5830-5837,585,586,588$ \\
Cancert & $140-172,174-188,190-195,200-208$ \\
Metastatic cancert & $196-198,1990,1991$ \\
Severe liver disease & $5722-5724,5728$ \\
HIV & $042-044$ \\
\hline
\end{tabular}

ICD-9-CM: International Classification of Diseases-Clinical Modification, 9th edition. †Bladder cancer is excluded from this condition. 
Minnillo et al.

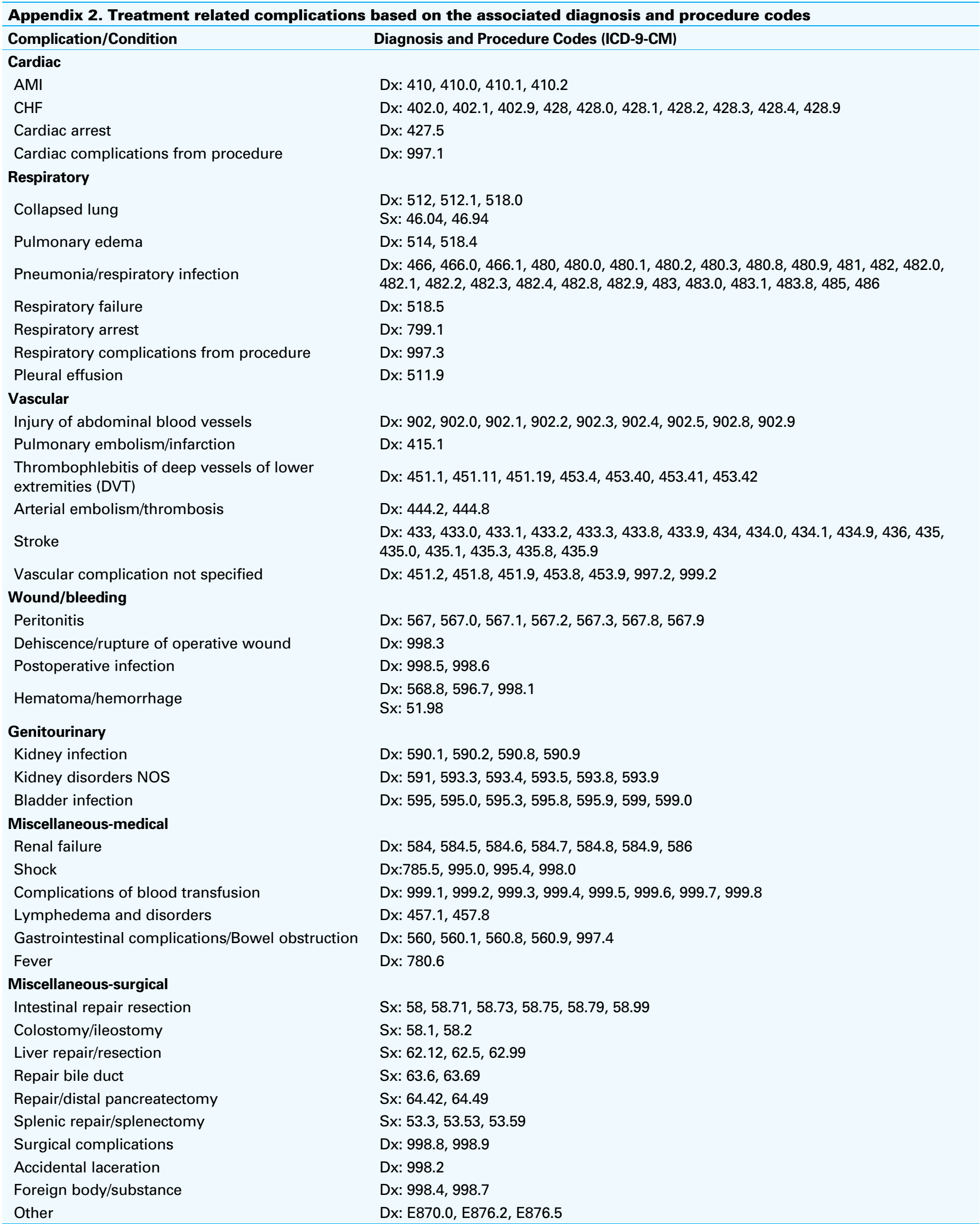

ICD-9-CM: International Classification of Diseases-Clinical Modification, 9th edition; AMI: acute myocardial infarction; CHF: congestive heart failure; DVT: deep vein thrombosis; NOS: no evidence of disease. 